\title{
The micromorphology of the blesbuck louse Damalinia (Damalinia) crenelata as observed under the scanning electron microscope
}

\section{M.L. Turner}

Turner, M.L. 2003. The micromorphology of the blesbuck louse Damalinia (Damalinia) crenelata as observed under the scanning electron microscope. Koedoe 46(1): 65-71. Pretoria. ISSN 0075-6458.

The blesbuck is an important game animal on many game farms and reserves in South Africa. Damalinia crenelata, a biting louse, host-specific to the blesbuck, feed upon epidermal debris of this antelope, leading to severe skin irritation and dermatitis. Symptomatic scratching by the host aggravates these conditions. High infestations may lead to decreased population numbers. Live lice were collected from a blesbuck in the Rietvlei Nature Reserve and prepared for selectron microscopic investigation. Micrographs were recorded. The SEM investigation revealed several micromorphological features not previously described in $D$. crenelata. Besides the obvious anatomical differences in the reproductive organs of the male and female, several other differences were noted. The antennal flagellae showed morphological differences as well as certain features on the ventral surfaces of the head. Dorsally the forehead was markedly emarginated and showed an acute invagination (clypeo labral suture) in the pulvinal area. The ventral surface of the head clearly demonstrated the structures of the preantennal regions such as ventral carina, pulvinus, labrum, mandibles and clypeus. The epipharynx appeared as an underlying extension of the labrum. The rims of the clypeus were more raised and thickened in the female than in that of the male. The mandibles were not notched and were noted to be angular in shape. The three segments of each of the antennae of the male were thicker and more robust than than those of the female. This could suggest sexual dimorphism in this species. The sensilla basoconica comprised 10 pegs. Pit organs were seen within the pore organs. The prothorax and mesothorax were clearly distinguished. The abdominal segments showed six pairs of spiracles. The male and female terminalia were confirmed to be strongly sexually dimorphic. The three pairs of legs each terminated in a single, long and slender, claw.

Key words: Damaliscus dorcas phillipsi, blesbuck, SEM, Damalinia crenelata.

M.L.Turner, Electron Microscope Unit, Medical University of Southern Africa, 0204, Republic of South Africa.

\section{Introduction}

The blesbuck (Damaliscus dorcas phillipsi) is an important game animal and is ranched on many game farms and reserves in South Africa. Damalinia crenelata (Piaget, 1880) is a Mallophagen type of ectoparasite of the blesbuck (Ledger, 1980). The mallophaga (biting lice) use their mouthparts in a scraping and rasping action when feeding upon epidermal debris of the host, leading to severe skin irritation and dermatitis. Symptomatic scratching of the host aggravates these conditions (Green et al. 2001). When infestations of these host-specific lice (Ledger
1980) are high, the growth of young animals may be stunted leading to decreased population numbers.

The superorder Psocodea comprises two orders, one of which is the Phthiraptera. Phthiraptera have no free living stages and are all obligate ectoparasites found on almost all avians and approximately a quarter of all mammals (Smith 2000; Soler Cruz 1995). Lice are further divided into four groups namely Amblycera, Ischnocera, Rhyncophthirina (a monogeneric group found on elephants and warthog only), and Anoplura. The former three are of the biting (mallophaga) 


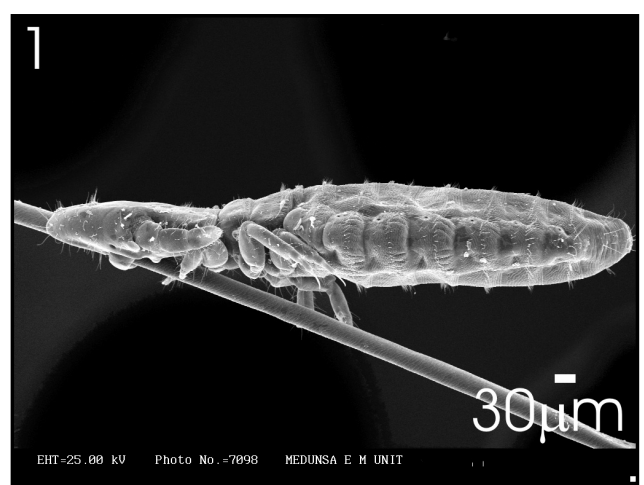

Fig. 1. A SEM micrograph of Damalinia crenelata anchored to a hair of a blesbuck.

type whilst the latter (Anoplura) are commonly known as the sucking type (Smith 2000). The genus Damalinia comprises three subgenera (Soler Cruz \& Martin Mateo 1998,): D. (Trichlipeurus), D. (Cervicola) and D. (Damalinia) (Bovicola) (Ledger 1980). It was previously mentioned that $D$. crenelata is of the mallophagen or biting type of louse.

An extensive literature search revealed that D. crenelata (Fig. 1), has to date, not been fully or completely described under the scanning electron microscope (SEM). Although certain authors such as Soler Cruz \& Martin Mateo (1998, 2001) have made mention of $D$. crenelata where, they compared structures of the preantennal region as well as the sensory equipment of the antennal flagellum of several species of Damilinia and Smith (2000) recorded the male antennal scape outline. No detailed ultrastructural investigations were found. It was hence concluded that the micromorphology of $D$. crenelata was incomplete and an attempt was thus made to correct this paucity in the literature.

\section{Materials and methods}

Live lice were collected during an organised culling session from a blesbuck in the Rietvlei Nature Reserve situated to the south east of Pretoria. The blesbuck seemed healthy and was not heavily infested, thus only 3 lice ( 2 males and 1 female) were found. The male lice were found in the proximity of the genitalia whilst the female was found at the base of the left ear. The lice were processed according to the method as described by Turner (2002) for the waterbuck louse (Bovicola hilli).

The specimens were fixed in $70 \%$ ethanol. Graded alcohol ( $70 \%, 80 \%, 96 \%$ and absolute) was used to achieve dehydration of the lice. After dehydration the specimens were sonicated in absolute alcohol for approximately 1 minute. The lice were dried at the critical point of medical wet carbon dioxide, after which they were mounted and fixed onto standard SEM pin type aluminium stubs with double-sided tape. The lice were sputter-coated with gold for 2 minutes at $12 \mathrm{~mA}$ under vacuum and in the presence of argon gas. The coating procedure was repeated from different angles to reduce the effects of charging when rotating and tilting the specimen stage (holder). The specimens were viewed in a Leica Stereoscan 420 SEM at $6-12 \mathrm{kV}$ with $3-12 \mathrm{~mm}$ working distances.

Although the working distances varied due to the tilting of the specimen stage, good resolution and contrast was obtained by optimally manipulating the beam of electrons. The accelerating voltages varied proportionately to the working distances during tilting. The specimens were tilted from $0^{\circ}-90^{\circ}$ and rotated from $0-360^{\circ}$ thus covering all planes of the $x, y$ and $z$ axes through the specimens. The tilting and rotation was performed for the sole purpose of obtaining the maximum anatomical exposure of the surface of each louse. The contrast was set to $14 \%$ whilst the brightness was kept at $32 \%$. A $30 \mu \mathrm{m}$ aperture was placed in the path of the beam to lessen the negating effects of diffraction and interference of the accelerated electrons. Micrographs were recorded as tagged information files (*.tif) and later printed onto Hewlett Packard (Premium Glossy Photographic Paper with a Hewlett Packard (1120C Professional Series printer.

\section{Results}

The SEM investigation revealed several micromorphological features not previously described in D. crenelata. Besides the obvious anatomical differences in the reproductive organs of the male and female, several other differences were noted. The antennal flagellae showed morphological differences 
as well as certain features on the ventral surfaces of the head.

The following specialisations and anatomical features were revealed when the male lice were viewed under the SEM:

Dorsally the forehead was markedly emarginated anteriorly and revealed a rather acute invagination when compared to Bovicola hilli an ectoparasite from the waterbuck Kobus ellipsiprymnus (Bedford 1934; Turner 2002) and Bovicola caprae, the domestic goat louse (Green et al. 2001). Ventrally, both the male and female showed the acute invagination in the pulvinal area. That of the female was slightly deeper with the apex of the invagination broader and more rounded than that of the male.

The ventral surface of the head clearly demonstrated the structures of the preantennal regions such as ventral carina, pulvinus, labrum, mandibles and clypeus according to Soler Cruz \& Martin Mateo (2001) in both the male and female specimens of $D$. crenelata (Fig. 2). However, it must be noted at this point that the terminology in this field of research has yet to be agreed upon by those whom intensely devote their time to studying these creatures. Standardisation would facilitate future communication amongst researchers. In this investigation we shall adopt the terminology of Soler Cruz \& Martin Mateo (2001).

The structure which is commonly known as the labrum and situated below the pulvinus, revealed that the epipharynx (Green et al. 2001; Symmons 1952 \& Turner et al. 2002) had dentate scale-like structures used for rasping and scraping the epidermal surface of the host. Described here for the first time in D. crenelata, the epipharynx appeared either as a separate structure or as an underlying extension or continuation of the labrum (Fig. 3). This was clearly distinguishable from the labrum which was different in its structure and in the arrangement of its scales. The scales of the labrum did not show the dentate structures of the epipharynx (Fig. 4). The labrum of D. crenelata matched the descriptions of Soler Cruz \&

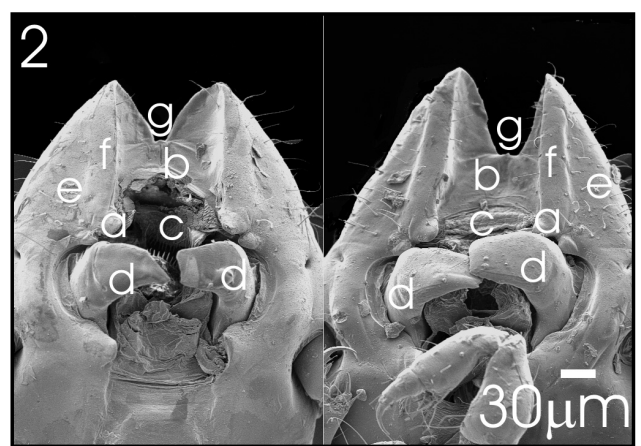

Fig. 2. The ventral surface of the head showing the structures of the preantennal regions (a) ventral carina, (b) pulvinus, (c)labrum, (d) mandibles, (e) clypeus, (f) thickened rim of the clypeus (g) invagination of the forehead, in both the male (left) and female specimens of Damalinia crenelata.

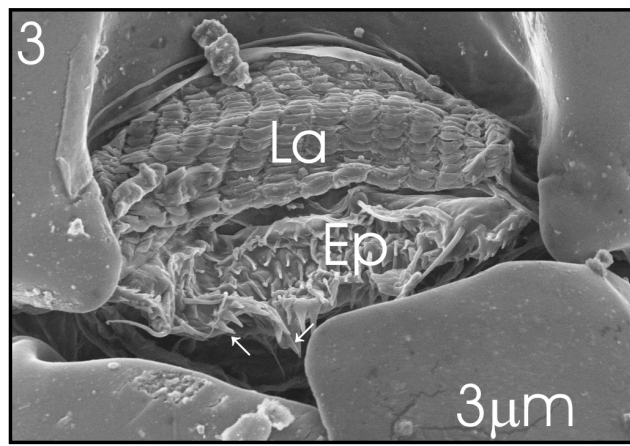

Fig. 3. The epipharynx (Ep) with its dentate structures (arrows) appeared as a separate structure underlying the labrum (La).

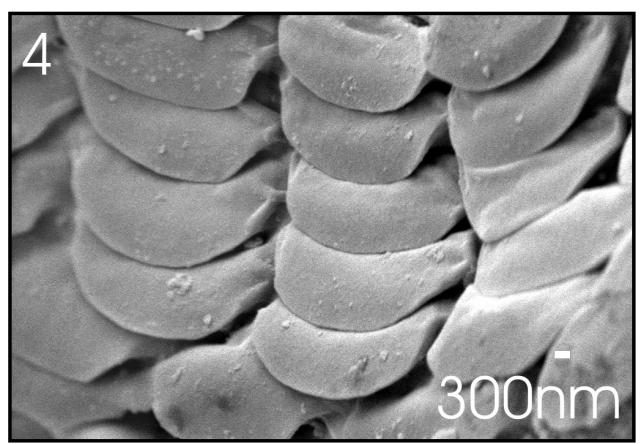

Fig. 4. The scales of the labrum did not reveal dentate structures and matched the micrograph of Soler Cruz \& Martin Mateo (2001) thus confirming the species. 


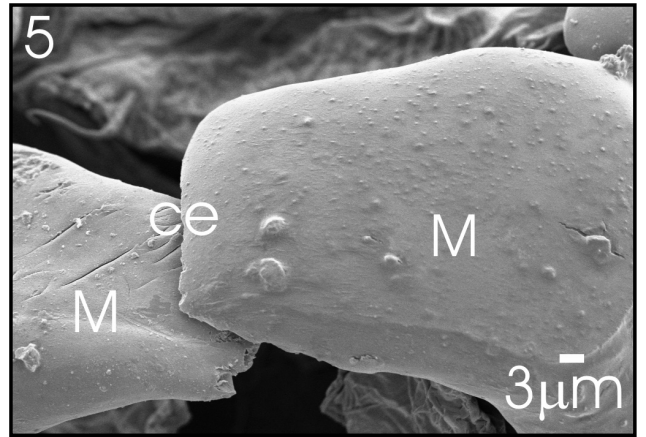

Fig. 5. The mandibles (M) were broad and flat and were not notched on the cutting edges (ce).

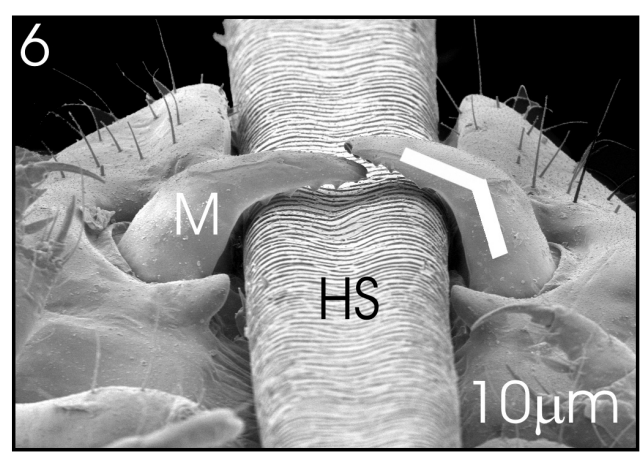

Fig. 6. The micrograph suggests that the hair shaft (HS) of the blesbuck antelope is not round in cross section but more oval in shape thus contributing to the angular (lines) adaptation of the mandibles (M).

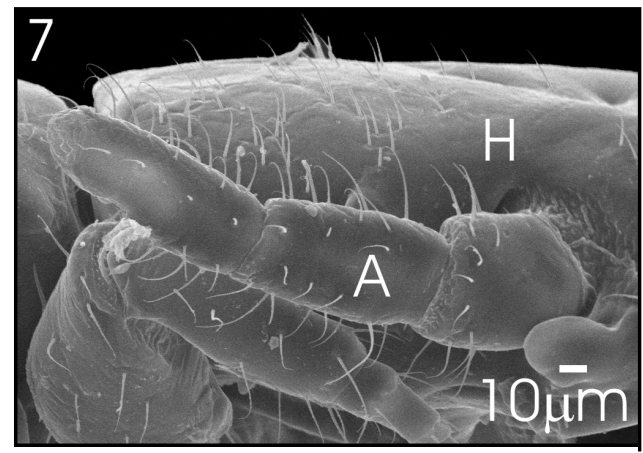

Fig. 7. The three segments of each of the antennae (A). $(\mathrm{H})=$ head.
Martin Mateo (2001) and confirmed the species.

The margins of the ventral carina (the thickened rims of the clypeus) bordering the medial groove (into which the host's hair snugly fits during anchorage and attachment) was notably more raised and thickened in the female, than in that of the male. The posterior part of the ventral carina was blunt and again confirmed the species as reported by Soler Cruz \& Martin Mateo (2001).

The mandibles were broad and flat and were not notched on the cutting edges thus no resemblance to apical teeth was found (Fig. 5). The oral surfaces were ridged to facilitate attachment to the hair of the host (Turner et al. 2002). Differences in the mandibular morphology of several species of Damalinia were accurately recorded by Soler Cruz \& Martin Mateo (2001). These authors noted a high degree of variability in the preantennal structures whilst also mentioning that the shape of the head could be an evolutionary adaptation due to the texture and density of the hairs of the host and possibly other environmental factors. An extremely interesting fact that should be noted was the angular shape of the mandibles, as opposed to the curved shape of those of $B$. hilli. It can clearly be seen in the micrographs that this fact is directly related to the shape of the host's hair. The micrograph suggests that the hair of the blesbuck is not round in cross section but more oval in shape, thus contributing to the angular adaptation of the mandibles of $D$. crenelata when compared to the curved arch-like mandibles of B. hilli (Fig. 6) (Turner et al. 2002).

The three segments of each of the antennae of the male were thicker and more robust than than those of the female (Fig. 7). The apex of the distal tip of the male antenna showed two teeth characteristic of the species (Soler Cruz \& Martin Mateo 1998) (Fig. 8). These conically shaped teeth were absent in the female. The teeth are probably used by the male whilst copulating. The 
toothed medial ridge on the entire distal segment of the antennae as observed in $B$. hilli (waterbuck louse) (Turner et al. 2002) was absent in D. crenelata.

The abovementioned occurrences could suggest sexual dimorphism in this species in microscopic examination of the heads only. This would also suggest that the head of the specimen investigated by Soler Cruz \& Martin Mateo (2001) was that of a female.

The sensory equipment on the last segment of $D$. crenelata showed that the sensilla basoconica comprised 10 pegs (Fig. 9). At higher magnifications the surfaces of the pegs were smooth with no evidence of pores whilst the tips were blunt (Soler Cruz \& Martin Mateo 1998). Viewed at an angle different to that of Soler Cruz \& Martin Mateo (1998), it could be suggested that some of the tips might contain a pore but due to debris, this fact could not be verified. The inner face of the segment revealed a complex of two pore organs (sensilla coeloconica) and three adjacent plate organs with their characteristic radiating form that does not resemble a pore-like structure (Fig. 10). Again the terminology of the antennal sensoria is controversial and future standardisation is necessary. An excellent contribution was made by Soler Cruz (1995) in order to clarify some of the terms used in the antennal sensory complex of Phthiraptera but unfortunately controversy still exist. Unlike the findings of Soler Cruz \& Martin Mateo (1998), pit organs (tuft organs) were seen within the pore organs (Green et al. 2001) or sensilla coeloconica (Soler Cruz \& Martin Mateo 1998). The angles at which the specimens are viewed at, the age of the specimens, fixation and preparatory techniques et cetera, would suggest that it would not always be possible to view each and every detail of the antennae and this would contribute to the fact that the pit organs were not noted by these authors.

Dorsally, the prothorax and mesothorax were clearly distinguished from one another and were not fused. Two large thoracic spiracles situated laterally on each side of the pro-thorax were noted (Fig. 11). The filtering appa-

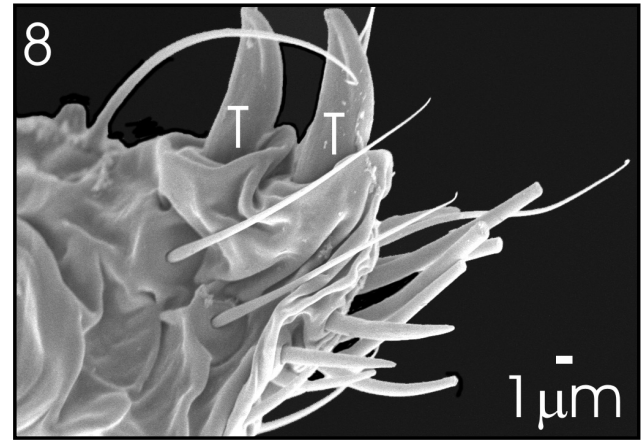

Fig. 8. The apex of the distal tip of the male antenna showed two teeth $(\mathrm{T})$ which are used during copulation.

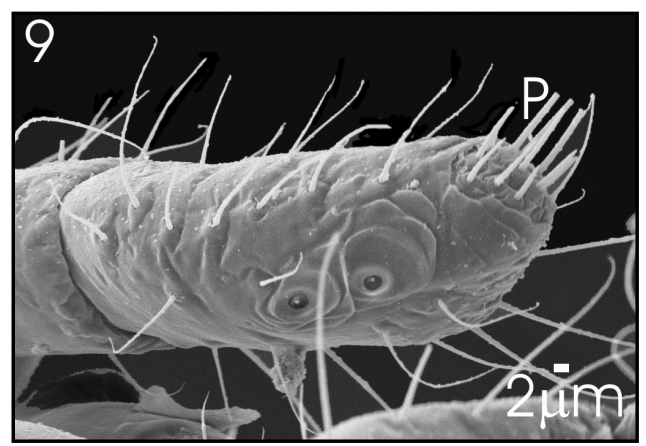

Fig. 9. The sensory equipment on the last segment of Damalinia crenelata showed that the sensilla basoconica comprised 10 pegs.

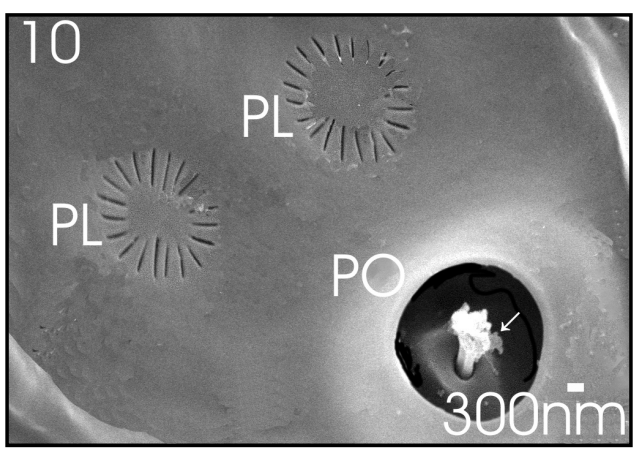

Fig. 10. A pore organ (PO) with adjacent plate organs (PL) which were found on the last antennal segment. $($ Arrow $=$ tuft or pit organ) 


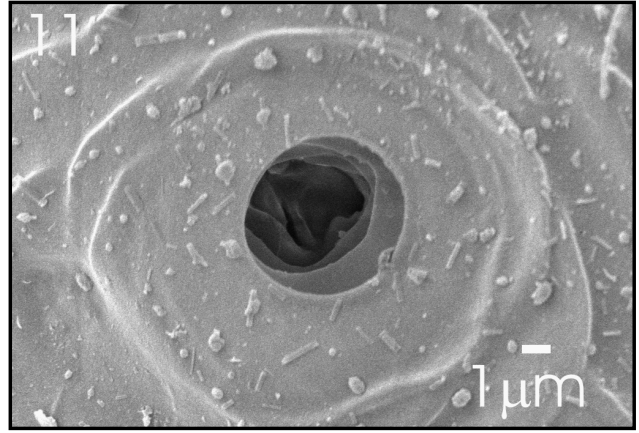

Fig. 11. A large thoracic spiracles was situated laterally on each side of the pro-thorax.

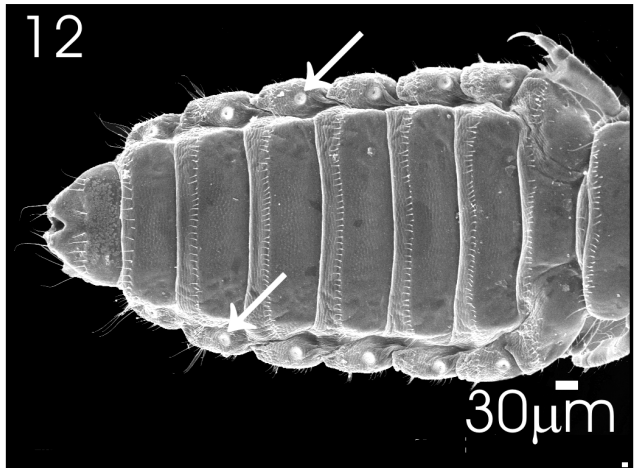

Fig. 12. A dorsal view of the abdomen showing 6 pairs of respiratory spiracles (arrows).

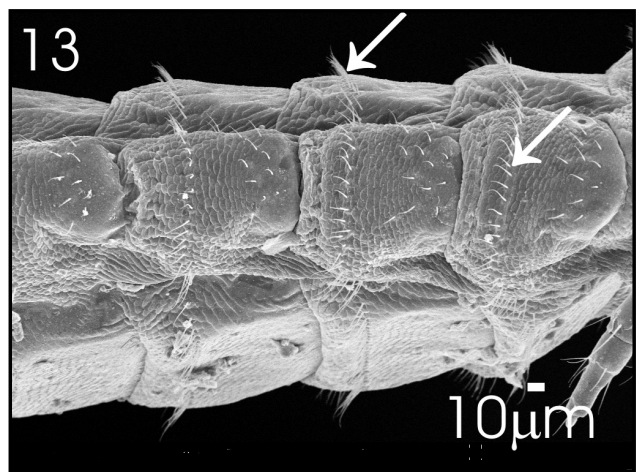

Fig. 13. Lateral view of the abdomen showing single transverse rows of short setae (arrows) situated on the dorsal and ventral surfaces of each segment.

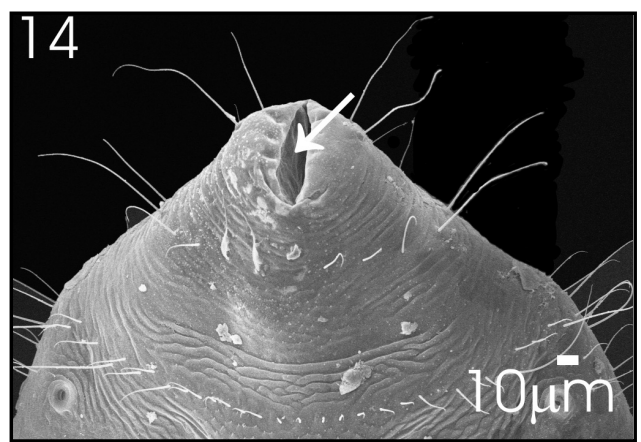

Fig. 14. The genital opening of the male showed no setae surrounding the slit (arrow).

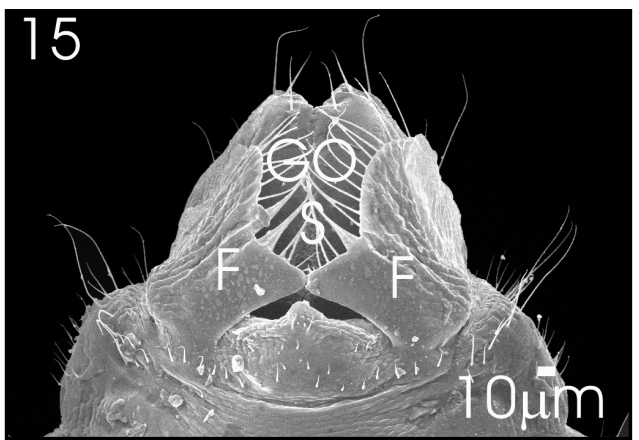

Fig. 15. Characteristic posterio-lateral flaps (F) of the female gonopods with a single terminal row of long setae (S) on each flap. ( $\mathrm{GO}=$ genital opening).

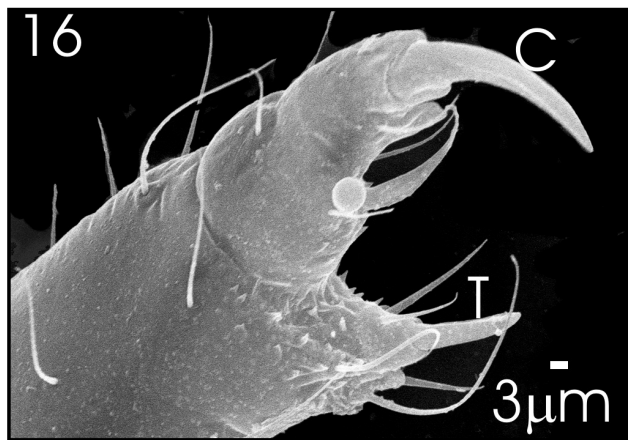

Fig. 16. The legs terminated in a claw (C) that closed against an appositional distio-tibial thumblike seta $(\mathrm{T})$. 
ratus of the spiracles had honeycomb-like inner surface structures.

The abdominal segments showed 6 pairs of spiracles (Fig. 12) and displayed well developed tergites and sternites with single transverse rows of short setae situated on the dorsal and ventral surfaces of each segment (Fig. 13).

The male and female terminalia were confirmed to be strongly sexually dimorphic. The genital opening of the male was slit-like and had no setae surrounding the slit (Fig. 14). This could be of some taxonomic importance as regards other species of Damalinia (syn. Bovicola) as previously reported by Green et al. (2001) in B. caprae and by Turner et al. (2002) in B. hilli. The aedeagus could not be demonstrated in any of the male specimens and no obvious flaps covered the genital opening. The female had a pair of characteristic posterio-lateral flaps with a terminal single row of long setae on each flap, probably assisting in the placement of the egg during the ovipositing thereof (Fig. 15).

The three pairs of legs each terminated in a single, long and slender, claw that closed against an appositional distio-tibial thumblike seta which when closed would form a perfect grasping organ around the hair of the host (Green et al. 2001) (Fig. 16). The claws of the first pair of legs were shorter than the second and third pair. The third pair being the most robust.

This investigation was performed in order to assist entomologists, veterinarians and biologists, in this very rare field of research, in the identification of this species as well as for the purpose of comparative studies. The study does however not purport to be taxonomic in nature but rather to serve as a guide to further studies on Damalinia crenelata.

\section{Acknowledgements}

The author would like to express his gratitude to the manager of the Rietvlei Nature Reserve, Mr Riaan Marais. Miss Chantelle Baker for her support during the investigation. Mr Cecil Labuschagne for his assistance during the collection of specimens. Professor Edward Green for sharing his knowledge and expertise in this particular field of research.

\section{References}

BeDFord, G.A.H. 1934. Description of new species of Anoplura parasitic on antelopes and hairs. Onderstepoort Journal of Veterinary Science and Animal Industry 2(1): 41-48.

Green, E.D., M.L. Turner \& P.J. Sebei. 2001. The functional micromorphology of the goat biting louse (Bovicola caprae). Proceedings of the Microscopy Society of southern Africa 31: 62.

LEDGER, J.A. 1980. The Arthropod parasites of Vertebrates in Africa south of the Sahara. Volume 4: Phthiraptera (Insecta). Johannesburg: South African Institute for Medical Research. (Publications of the South African Institute for Medical Research 56: 198-199.)

SMITH, V.S. 2000. Avian louse phylogeny (Phthiraptera: Ischnocera): A cladystic study based on morphology. $\mathrm{PhD}$ thesis, University of Glasgow.

Soler CRUZ, M.D. 1995. Antennal sense organs of Phthiraptera (Insecta). Scanning electron microscopy of several species of Anoplura. Micron 26(1): 7-14.

Soler Cruz, M.D. \& M.P. Martin Mateo. 1998. Sensory equipment of the antennal flagellum of several species of Damalinia (Phthiraptera: Thrichodectidae). Micron 29(6): 431-438.

Soler Cruz, M.D. \& M.P. Martin Mateo. 2001. Structures of the preantennal region of several species of Damalinia (Phthiraptera: Trichodectidae). Journal of Medical Entomology 38(6): 802808.

Symmons, S. 1952. Comparative anatomy of the mallophagan head. Transactions of the Zoological Society of London 27: 349-436.

Turner, M.L., C. BAKER \& R. MARAis. 2002. A scanning electron microscope investigation of the waterbuck louse Bovicola hilli found at the Reitvlei Nature Reserve. Koedoe 45(1): 59-63. 